\title{
Desestabilizar el discurso Arte feminista del underground porteño
}

\author{
Destabilizing the Speech \\ Feminist Art of Buenos Aires Underground
}

\author{
Ana Laura Suzzi \\ suzzi.analaura@gmail.com \\ Facultad de Bellas Artes. Universidad \\ Nacional de La Plata. Argentina \\ Recibido: $10 / 11 / 2018$ \\ Aceptado: 3/3/2019
}

\begin{abstract}
Resumen
En este trabajo pretendemos reflexionar sobre las primeras apariciones y aportes del arte feminista en la Argentina posdictadura tomando como referencia la exhibición Mitominas I. Dicha muestra tuvo el propósito de impugnar el lugar de la mujer en el arte. Considerada una de las primeras exposiciones en abordar y complejizar esta temática en Buenos Aires durante la década de 1980, resultó pionera en el cuestionamiento y la visualización de la mujer en cuanto constructo social creado desde la antigüedad. Para este trabajo nos valemos de artículos periodísticos y de bibliografía que aborda el tema. Asimismo, tomamos como ejemplo dos obras que buscaron denunciar y romper con la representación estereotipada de la mujer.
\end{abstract}

\section{Palabras clave}

Feminismo; arte; under, Buenos Aires; Mitominas

\begin{abstract}
In this work we aim to ponder on the first appearances and contributions of feminist art in Argentina post dictatorship taking as a reference the exhibition Mitominas I, considered one of the first demonstrations that approached and made complex the subject in Buenos Aires during the 1980s, being a pioneer in the questioning and visualization of women as a social construct created since antiquity. The exhibition was intended to challenge women's place in art. For this writing we use journalistic articles and bibliography referred to the subject. We take as an example two works that sought to break with the stereotyped representation of women.
\end{abstract}

\section{Keywords}

Feminism; Art; Under; Buenos Aires; Mitominas 


\section{AVANCES

DE TR

Los estudios sobre feminismo(s) han abierto un abanico de abordajes específicos en diversas áreas y temáticas. Sin embargo, el desarrollo de la problemática que vincula arte y feminismo es menor, en nuestro país, en comparación con estudios relativos al tema en otras áreas, que llevan varias décadas de investigación como los que refieren al mundo laboral o a las ciencias, por ejemplo- . Si bien en la actualiad el debate sobre el feminismo atraviesa a la sociedad argentina y se encuentra abierto y vigente-se actualiza a diario-, lo cierto es que no siempre fue así y menos aún en Latinoamérica. Este ha sido un proceso cultural poco estudiado que comenzó a ampliarse a partir de la década del setenta hasta nuestros días, aunque aún falta mucho por explorar.

En la actualidad, hay una gran cantidad de estudios sobre género y se están realizando cada vez más investigaciones y trabajos en este campo. En nuestro país, la ola feminista está creciendo en cuanto a cifras. Esto se puede constatar en todos los eventos que han congregado grandes multitudes de mujeres que se reunieron y manifestaron, como los Encuentros Nacionales de Mujeres, cada vez más masivos y notorios, o las marchas emprendidas por el aborto legal, seguro y gratuito, en contra de la violencia de género - «Ni una menos»-, en conmemoración del Día Internacional de la Mujer —el 8 de marzo-, etcétera. También se puede observar en las redes sociales, donde cada vez circula más información de este tipo: mujeres que relatan acosos y distintos tipos de violencia que han sufrido vinculadas al patriarcado, al igual que en variadas notas, entrevistas y distintas expresiones artísticas en que se refieren, interpelan y denuncian hechos de estas características.

Lo anterior da cuenta y deja a la vista cuestiones y problemáticas que en el pasado no solo se mencionaban poco, sino que, cuando eran comentadas, eran puestas en tela de juicio por muchas personas, que desmerecían la palabra de las denunciantes, tratándolas de mentirosas o de emisoras de falsos testimonios. Actualmente, el cambio es notorio. Por ejemplo, se han creado distintas instituciones para atender específicamente problemáticas de mujeres o, en versión ampliada, cuestiones de género. Desde diferentes epistemologías y enfoques se está estudiando el feminismo, enriqueciéndolo y dejando entrever que estamos en pleno proceso de deconstrucción en cuanto a la imagen y a las formas de pensarse mujer.

El feminismo actual redefine sus parámetros en varios sentidos. En primer lugar, al enlazar en redes transgeneracionales la sororidad y el antipatriarcalismo. En segundo lugar, al revisar las estrategias y las experiencias de las artistas, que permiten socializar prácticas y poéticas disidentes, examinar propuestas y debates, y actualizar las agendas, produciéndose así un diálogo y una 


\section{AVANCES

discusión entre pasado y presente. En tercer lugar, al superar el binarismo hombre/mujer mediante la activación de otras diversidades que fueron incluyéndose en debates de género y desafiando el androcentrismo. En cuarto lugar, al definirse como política transformadora, mediante la pedagogía. En el campo del arte, específicamente, el conocimiento de aquello que muchas artistas desconocidas plantearon implica hacerse de un tesoro de recursos, un conocimiento que es emancipador por sus intervenciones poéticas. Finalmente, la historización de la política poética o la poética política en su lucha emancipadora nos acerca a los activismos pasados y presentes, siendo todos ellos procesos de búsqueda, todas experiencias para comprender, aprender y continuar.

Un debate corriente en este proceso que está siendo es definir a qué denominamos arte feminista. Como afirma María Laura Rosa (2014): «Sin desconocer la heterogeneidad que esconde el término arte feminista, éste suele ser útil para denominar a todas aquellas obras, sean colectivas o individuales, que denuncian y buscan subvertir el sistema de inequidad que afecta a los géneros» (p. 16). De acuerdo con esta definición es que nos disponemos a abordar la muestra Mitominas I.

\section{Feminismo posdictadura}

La recuperación de la democracia en 1983, luego de años de dictadura en nuestro país, fue el contexto que permitió la realización de exhibiciones que problematizaron el rol de la mujer en nuestra sociedad y sentaron precedentes artísticos y culturales por medio de los debates y las obras que se expusieron.

Desde los años setenta las historiadoras del arte develaron que tanto su disciplina como la formación artística las excluía. Constataron que las mujeres han tenido y tienen menos presencia, menos muestras, menos honores y premios ganados, es decir, que ocupan lugares subordinados en la historia del arte y en los puestos de trabajo. Así, al no poder tener una apropiada educación y formación, se generaba una injusta y desigual competencia en el campo artístico. Desde entonces, se dio un boom del activismo feminista y se inició un camino de transformación. El arte comenzó a mostrar otros cuerpos, distintos, que rompían con los cánones, y también a ofrecer herramientas para poder liberarse, pensar otras corporeidades. De este modo, el cuerpo femenino se constituyó en un lugar en disidencia.

Sostiene Rosa (2013) que el cuestionamiento implica imbricar políticamente lo público y lo privado, de tal manera que «el arte feminista transforma lo cotidiano en objeto estético, en categoría pública, para evidenciar el sistema de inequidad ejercido sobre las 


\section{AVANCES}

DE TRABAJOS

1 Monique Altschul (1938) es Licenciada en Letras por la Universidad de Buenos Aires (UBA). Figura referente del feminismo argentino, fue la principal organizadora de las exposiciones de Mitominas realizadas en el Centro Cultural Recoleta. Fue premiada y honrada por diversas organizaciones, tanto nacionales como internacionales, por su trabajo, dedicación y lucha para con los derechos de las mujeres. mujeres en todos los ámbitos de la vida» (p. 73). Así, lo que sucede intrahogares puede atravesar las paredes y visibilizar relaciones desiguales, promover la reflexión, la deconstrucción, la impugnación, y agenciar prácticas para cambiar. En ese sentido, Mitominas I se trató de una propuesta de arte político.

\section{Mitominas I}

La muestra colectiva Mitominas I fue realizada en Argentina en los años ochenta. Se llevaron a cabo dos exposiciones en el Centro Cultural Ciudad de Buenos Aires (hoy Centro Cultural Recoleta): la primera, en 1986, con el auspicio de la Secretaría de Cultura de la Municipalidad de la Ciudad de Buenos Aires y de la Dirección de Artes Visuales de la Secretaría de Cultura de la Nación; la segunda, en 1988, auspiciada por la Secretaría de Desarrollo Humano y Familia, la Subsecretaría de la Mujer — creada el año anterior-, el Programa Mujer, Salud y Desarrollo del Ministerio de Acción Social y la Embajada de Francia. En ellas se presentaron obras efímeras, performances, pinturas, esculturas, escrituras, poesías y cine-debate, pertenecientes a lo que sería el underground de Buenos Aires; obras siempre en diálogo con el público, dado que los espectadores y las espectadoras eran parte de las acciones. El contexto era experimental. En su origen, la exposición estuvo organizada por Monique Altschul. ${ }^{1}$ Participaron gran cantidad de mujeres, feministas y no feministas, con ideas políticas, posicionamientos, procedencias e ideologías distintas.

A partir de esta muestra, intentaremos dar cuenta de que la utilización de nuevas formas de representación, tanto en Mitominas como en la escena artística en general, incrementó las formas de producir y expresar problemáticas de género y feminismo. Allí se cuestionó tanto la mitología europea como la americana, dado que ambas fueron creadoras de imaginarios sobre la idea/imagen de mujer. El propósito de la exhibición fue reflexionar críticamente sobre el lugar que ocupamos en la construcción histórica del mito y en la sociedad.

Como alude el título de la muestra, Mitominas I, las artistas retomaron y resignificaron la palabra mito desde diversas perspectivas, enfatizando en la Grecia antigua y concluyendo que la formación del patriarcado comienza en la Antigüedad. El análisis arrojó respuestas sobre creencias, formas sociales, actitudes normadas y conductas ya establecidas que construían estos relatos y sus personajes. En lo que refiere a la mitología clásica, las participantes evidenciaron y sometieron a crítica la imagen de la mujer a través de personajes como Penélope, la mujer que espera; Afrodita, la mujer pecadora y sexualizada; Pandora, la mujer que 
origina todos males; Atenea, la mujer fuerte y estratégica en la toma decisiones; figuras que fueron destacadas en las obras expuestas (Rosso, 2016). De esa manera, se fueron fijando relatos y se configuró una imagen de la mujer que prevalece actualmente en amplias geografías.

Las expositoras no debían ser necesariamente feministas ni artistas, más bien debían proponerse, participar y aportar ideas para trabajar la temática desde una posición crítica que concluyera en un resultado visual. Ellas produjeron un manifiesto titulado Mito, en el que se lee:

\footnotetext{
Mito es todo lo que congela. ¿Congela qué? Creencias, actitudes, y sobre todo conductas. Entonces: hay que ser fiel como Penélope, pecadora como Eva, madre ejemplar como Andrómaca, enamorada (silenciosa) hasta la muerte como Eco, santa como María, arrepentida como Magdalena, diabólica como Lilith, imprudente como Pandora, y así hasta el infinito, siempre.

Pero el mito «no existe ni persiste si no es por la palabra». Lo dijo Paul Valery, que algo sabía al respecto.

Y sin embargo, ah, sin embargo la palabra sirve para descongelar. Quien dice palabra, por supuesto, dice todo lo que habla. ¿No hablan acaso el color y las formas, no habla la danza?

Quien dice palabra dice color, forma, danza; dice luz, canto, movimiento; dice teatro, imágenes, sombras chinescas.

La palabra bajo todas sus formas, es la gran descongeladora.

Para eso trabajamos. Nos hemos agarrado de la palabra y sus formas para descongelar mitos y por lo tanto creencias, actitudes, y sobre todo conductas. Hemos trabajado en eso por espacio de un año. Aquí están nuestras conclusiones (Rosa, 2014, p. 79).
}

De este modo, las participantes develaron que la mujer es una construcción discursiva, una representación dinámica y cambiante en el espacio/tiempo.

Por otra parte, es importante destacar que Mitominas I fue una exposición de carácter interdisciplinario, que contó con una gran cantidad de producciones, variadas actividades y espectáculos. A su vez, al haberse articulado intercambios entre distintos lenguajes artísticos, se logró consolidar una visión nueva sobre la femineidad, muy innovadora para la época. Se produjeron espacios de reflexión y debate a través de talleres y mesas redondas, donde se discutieron varios temas - como la sexualidad, los roles de género, el trabajo doméstico, entre otros- en tanto construcciones sociales que afectan a las mujeres y a sus cuerpos, sujetos a mandatos y arquetipos que condicionan sus intereses, elecciones y libertades.

Con respecto a la difusión se publicaron anuncios tanto en la vía pública como en la prensa de entonces. Distintos periódicos 
como Clarín y La Nación, entre otros, sugirieron visitar la exhibición, mientras que algunas revistas publicaron entrevistas a las integrantes y descripciones de las obras (Rosa, 2014). Aunque estas notas periodísticas visibilizaron la muestra, no tuvieron alcance reflexivo y de concientización en ese momento, según afirma Rosa (2011):

Mitominas intervino activamente sobre los discursos dominantes de la época, apareció sobre un vacío crítico puesto que no se tienen antecedentes de exposiciones realizadas en Buenos Aires que cuestionen las construcciones discursivas y el papel de la mujer en el circuito institucional del arte (p. 370).

En el folleto elaborado para la muestra se alude al mito de Adán y Eva, de la tradición judeocristiana, mediante la representación de la serpiente y la manzana [Figura 1] como referencia simbólica del pecado y la tentación. En la exposición esta idea fue criticada mediante gran parte de las obras, en tanto su significado fue y es modular de la figura de mujer.

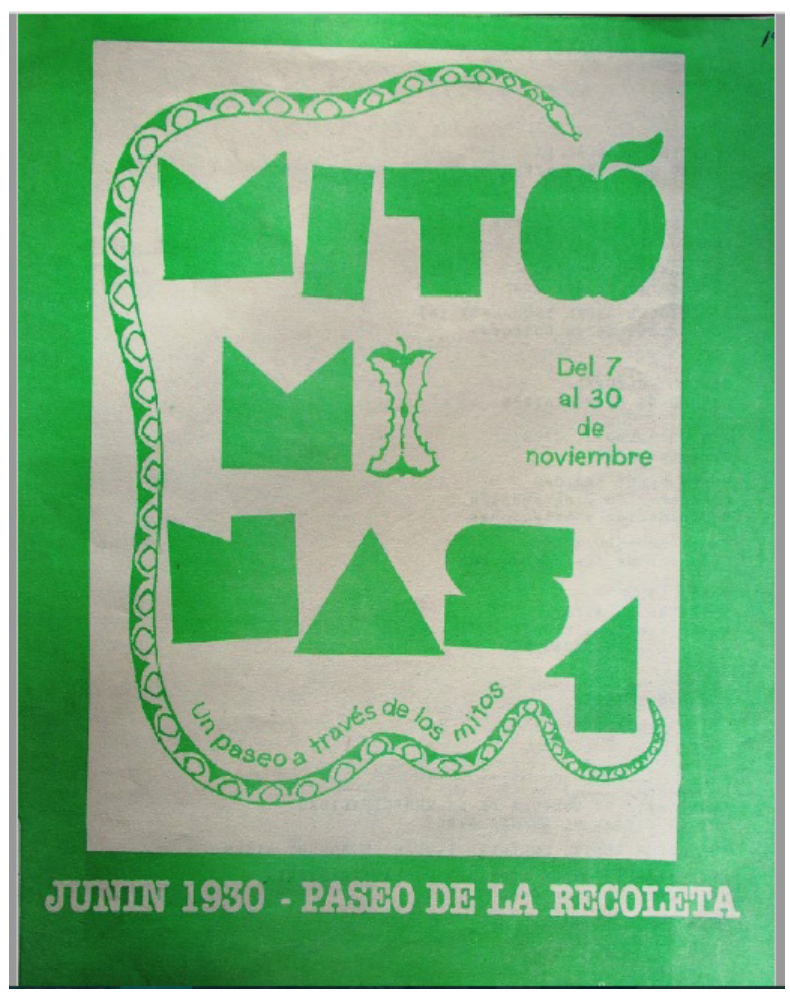

Figura 1. Cartel diseñado por Beba Braunstein (1986). Archivo Monique Altschul. Mitominas 1 


\section{AVANCES

En cuanto a la figura de artista, esta se concibió desde lo colectivo e interdisciplinario. Muchas obras expuestas eran anónimas, otras solo mencionaban el nombre de pila de sus productoras y pocas fueron las que se produjeron individualmente, predominando, de todas formas, lo grupal. Este colectivo se formó a partir de la idea de reivindicarse como mujeres en un sistema en el que se sentían rechazadas y oprimidas. Pese a que no todas se consideraban feministas, sí participaron como un grupo de mujeres empoderadas, que se manifestaron y se visibilizaron aprovechando las posibilidades del mundo del arte. En muchas producciones se observó, en las mismas acciones que mostraban, como se unía el trabajo colectivo con las vivencias personales.

\section{Producciones realizadas}

Con la finalidad de ejemplificar lo expuesto anteriormente, elegimos dos de las obras presentadas. La primera de ellas, llamada Oíd mortales el grito sagrado [Figura 2], consistió en la instalación de una jaula de gran tamaño donde permaneció una bailarina durante las tres semanas que duró la exhibición. El ultimo día, sujeta de un arnés, "sale por los aires» en una nube de humo (Altschul en Rosa, 2014, p. 88), simulando un vuelo como metáfora de libertad. Los materiales y objetos utilizados en esta obra -la jaula, el arnés, etcétera- fueron puestos o elaborados en el espacio por las participantes de la muestra.

Dado el contexto, se puede interpretar que esta obra aludía a la búsqueda de la emancipación de las mujeres. Si bien no se cuenta con una explicación clara de su título, si se tiene en cuenta la propuesta de esta instalación en aquel espacio/tiempo de la muestra, se puede pensar que hay una correlación simbólica con el verso del Himno Nacional argentino: "Oíd mortales el grito sagrado, libertad, libertad, libertad»; es decir, una correspondencia entre la emancipación de Argentina o la patria y la liberación de la mujer. A diferencia de las demás producciones de la muestra, esta implicó la presencia de una de las participantes como parte de la obra, por lo que los resultados fueron distintos para los espectadores y las espectadoras: quienes presenciaron únicamente la primera parte solo vieron, a la mujer enjaulada, con todo el contenido simbólico que eso significa. Quienes contemplaron únicamente el cierre -el último día-, en cambio, solo presenciaron la recuperación de la libertad. Con esta obra finalizó la exhibición. 


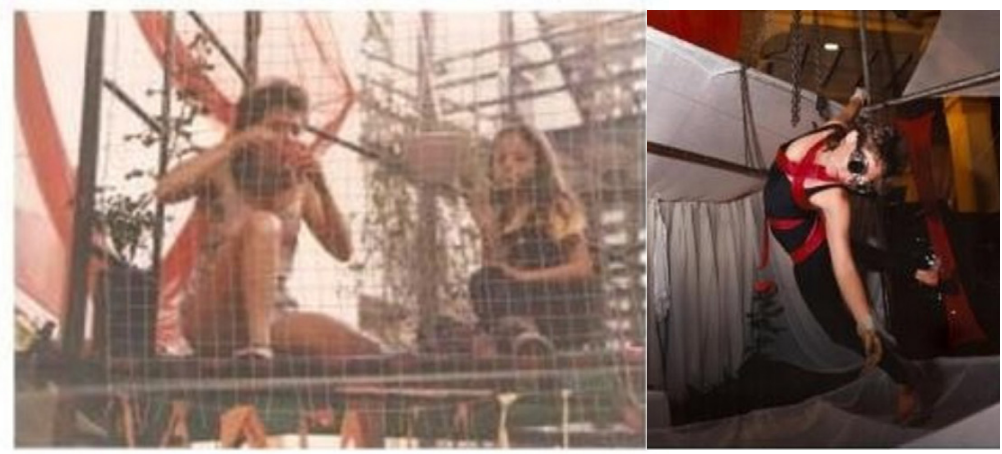

Figura 2 y 2.a. Jaula con bailarina de la obra "Oíd mortales el grito sagrado», Mitominas I (1986)

La segunda obra que analizaremos es una instalación que realizó Nora Correas [Figura 3]. En ella se representó a la mujer que espera a través de la figura de Penélope, siempre señalada en la historia como emblema de la pasividad, de la espera y de la fidelidad. La artista, perteneciente al campo del arte textil, produjo una obra donde se veía una gran cantidad de ropaje, de prendas de vestir, todas ellas de color blanco: camisones, sábanas, vestidos de novia, de comunión, medias, etcétera. Todo ese conjunto de telas se colocó a lo largo de una pared a modo de un enorme tapiz. La autora de la obra señaló que el color blanco en la mujer representaba «la cosa mudilla y receptora», «la rutina doméstica» (Correas en Rosa, 2014, p. 84). El recorrido de la obra finalizaba en una mancha roja: la mujer y la sangre. Así se propuso referir a esa espera prolongada, sin posibilidad de cambio, dentro de una casa, así como la mujer que se desea, con la idea de pureza al servicio de la familia y del hogar (Rosa, 2014).

Estas producciones, a modo de ejemplo, exponen el carácter, el contenido y el mensaje que alentaba a estas artistas que, además, utilizaron formas alternativas de representación. En este sentido, la muestra tenía dos propósitos fundamentales: hacer públicas las demandas y denuncias sobre su subalternización como mujeres y desafiar las tradiciones del campo artístico con propuestas alternativas. 


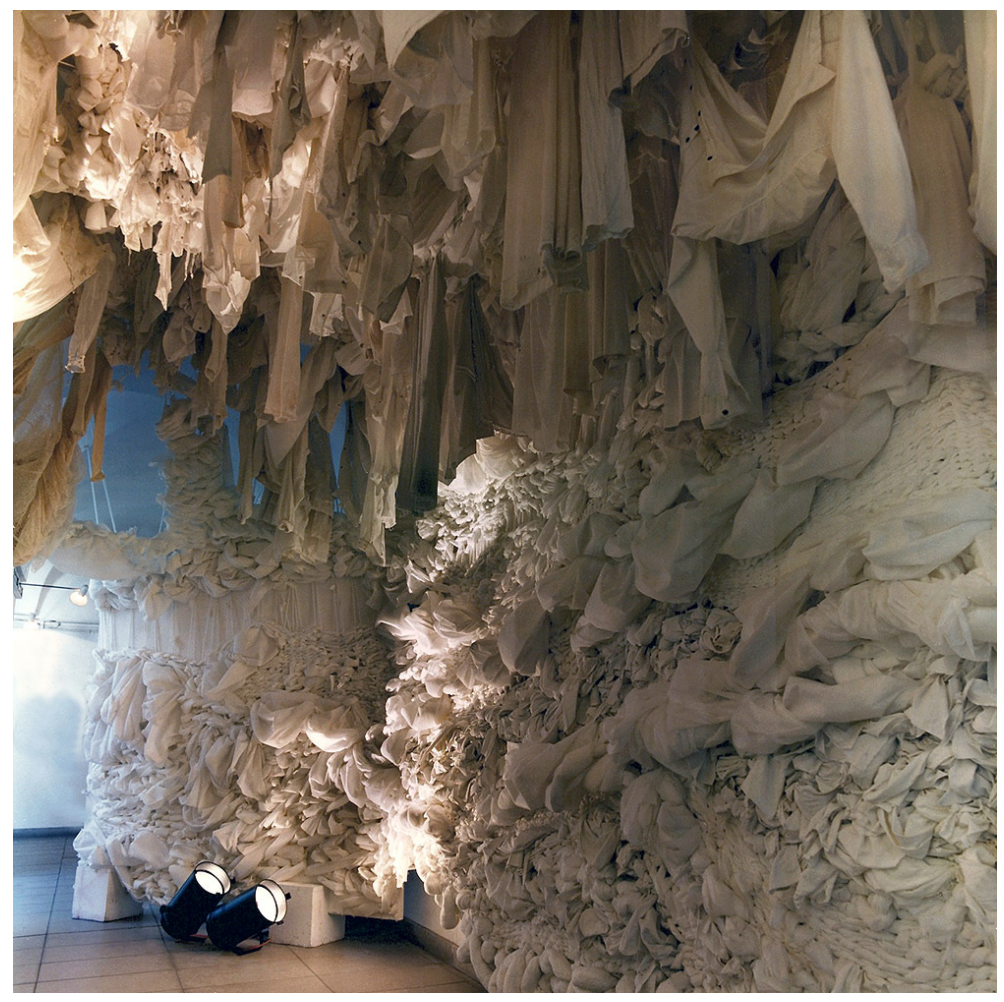

Figura 3. Nora Correas, Penélope. Archivo Monique Altschul. Mitominas I (1986)

\section{Palabras finales}

Por último, las obras de esta muestra plantearon su disconformidad con el lugar asignado a las mujeres, en sintonía con las luchas feministas de ese entonces, manifestándolo no solo de forma estética, sino también de denuncia y visualización. Mitominas / dio lugar a pensar y a continuar con la lucha política feminista desde el arte, lo que se extendió a Mitominas II, realizada en 1988. Esta segunda parte estuvo centrada en la relación de la sangre con la mujer, en la violencia de género y en $\mathrm{VIH}$, revisando los mitos en torno a ello. Su carácter plural y colaborativo también fue un rasgo fundamental, impugnando así el carácter individual del campo artístico. Lo que les importaba a las artistas era deconstruir y desestabilizar estereotipos y prejuicios, lo que se expresó también en la gran heterogeneidad de las producciones y propuestas. La idea de que el público participara fue positiva dado que quienes participaron se encontraron muy activos debatiendo y reflexionando sobre la temática. 


\section{AVANCES}

DE TRABAJOS

Mitominas I fue la primera exposición en Buenos Aires de índole transgresora, plural, política, colaborativa, interdisciplinaria y de carácter rupturista con la modernidad, que inicia debates sobre género y feminismo. Convergieron en ella la lucha por recuperar los espacios públicos, la unificación de voces de distintas mujeres en una misma muestra y el despliegue de prácticas sororas. Sobre ello, se destaca la cohesión lograda en pos del propósito, en tanto grupo heterogéneo y no conformado exclusivamente por artistas, así como también, la impronta interdisciplinaria, que diluye la jerarquización del campo artístico. Por todas esas razones, tanto Mitominas I como su sucesora, Mitominas II, aportan un valioso documento sobre las producciones artísticas del feminismo, las problemáticas abordadas y el clima underground que se vivía en aquellos tiempos en nuestro país.

En ese sentido, resulta una tarea fundamental recuperar la entrega de aquellas mujeres que plantearon propuestas nuevas, desestabilizando los lenguajes comunes del arte, las materialidades y los soportes. Asimismo, resulta esencial destacar la importancia de las obras de arte para con la sociedad ya que las mismas funcionaron y siguen haciéndolo como vehículo para manifestar las problemáticas y las luchas contra las injusticias sociales.

Así, como contradiscurso, las exposiciones Mitominas / y // encontraron su momento para emerger y expresar voces que habían sido silenciadas, ocultadas y denigradas. Utilizaron el arte para manifestarse - lejos de la norma, la disciplina, las reglas y la academia- y para mostrar otras subjetividades, otras formas de ser, otras maneras de pensarse y representarse en pos de concientizar y denunciar el hecho de que las mujeres han sido - y aún soninvisibilizadas y/o desestimadas por el arte androcéntrico.

\section{Referencias}

Altschul, M. (1986). Mitominas / [Exposición colectiva]. Buenos Aires, Argentina: Centro Cultural Ciudad de Buenos Aires.

Altschul, M. (1988). Mitominas II [Exposición colectiva]. Buenos Aires, Argentina: Centro Cultural Ciudad de Buenos Aires.

Rosa, M. L. (2011). Fuera de discurso. El arte feminista de la segunda ola en Buenos Aires (Tesis de doctorado). Recuperado de http://e-spacio.uned. es/fez/eserv/tesisuned:GeoHis-Mlrosa/Documento.pdf

Rosa, M. L. (2013). Fuera de Discurso: Las artistas en los bordes del canon de la historia del arte. Estudio de caso: Mitominas I y II (1986-1989). En Museo Nacional de Bellas Artes (Comp.), Seminario Historia del Arte y Feminismo. Relatos lecturas escrituras omisiones (pp. 73-82). Recuperado de http://patrimonioygenero.dibam.cl/651/articles-49719_archivo_01.pdf 
Rosa, M. L. (2014). Legados de Libertad. El arte feminista en la efervescencia democrática. Buenos Aires, Argentina: Biblos.

Rosso, L. (8 de julio de 2016). Derribando mitos. Página 12. Recuperado de https://www.pagina12.com.ar/diario/suplementos/las12/13-106992016-07-12.html 